\title{
Analisis Pemilihan Supplier Alat Tulis Kantor Dengan Metode Analitycal Hierarchy Process Pada PT. Bank XYZ Kantor Pusat
}

\author{
Gita Putri Ramanda ${ }^{1}$, Resista Vikaliana ${ }^{2}$ \\ Jurusan Manajemen Logistik, Fakultas Ilmu Sosial dan Manajemen, Institut Ilmu Sosial dan Manajemen STIAMI \\ Email : amoiiomaii28@gmail.com, ${ }^{1}$ resistav31@gmail.com ${ }^{2}$
}

\section{ARTICLE INFO}

\section{Article History}

Received : 24 Oktober 2019

Reviewed : 16 Oktober 2019

Published : 31 Oktober 2019

Available Online : 2 November 2019

\section{Keywords}

Pemilihan Supplier Alat Tulis Kantor,

Analitycal Hierarchy Process, Supplier Terbaik

\section{Keywords}

Office Stationery Suppliers, Selection,

Analitycal Hierarchy Process, The Best Supplier

\begin{abstract}
Penelitian ini diharapkan mampu memberikan informasi supplier mana yang sebaiknya dipilih oleh perusahaan dengan tetap melihat factor-faktor yang mempengaruhi kegiatan operasional perusahaan. Metode penelitian ini menggunakan deskriptif analitis dengan pendekatan kuantitaif. Sedangkan operasionalisasi variabelnya adalah harga, kualias dan pengiriman. Teknik pengumpulan data penelitian ini yaitu dengan wawancara pendahuluan untuk menentukan kriteria yang dinilai pada persepsi responden dan kuisioner untuk menentukan urutan dari kriteria yang didapat dari hasil wawancara pendahuluan. Dari hasil penilaian tingkat kepentingan Kriteria yang paling berpengaruh dalam pemilihan supplier alat tulis kantor pada PT Bank XYZ adalah kriteria kualitas dengan nilai bobot 0,46 . Kriteria selanjutnya yang berpengaruh adalah kriteria harga dengan bobot 0,42 serta kriteria pengiriman dengan nilai bobot 0,13 . Hal ini menunjukan bawah PT Bank XYZ mengutamakan kualitas yang tinggi untuk alat tulis kantor dikarenakan alat tulis kantor dengan kualitas baik akan berpengaruh pada operasional PT Bank XYZ.
\end{abstract}

This research is expected to be able to provide supplier information which companies should choose by keeping in view the factors that influence the company's operational activities. This research method used descriptive analytical with quantitative approach While the variables operationalization is price, quality and delivery. The research data collection technique is preliminary interviews to determine the criteria assessed on the respondents' perceptions and questionnaires to determine the order of the criteria obtained from the preliminary interviews results. From the assessment results of the importance level that most influential criteria in the selection office stationery suppliers at PT Bank XYZ are quality criteria with a weighting value of 0.46 . The next criteria that influence are the price criteria with a weight of 0.42 and the shipping criteria with a weight value of 0.13. This shows that PT Bank XYZ prioritizes high quality for office stationery because office stationery with good quality will affect the operations of PT Bank XYZ.

\section{PENDAHULUAN}

PT. Bank XYZ merupakan perusahaan yang bergerak dibidang pelayanan jasa. Pelayanan jasa perbankan adalah semua aktivitas bank, baik secara langsung maupun tidak langsung yang berkaitan dengan tugas dan fungsi bank sebagai lembaga intermediasi keuangan untuk menghimpun dana, menyalurkan dana, dan menerbitkan jasa bank lainnya. Di PT Bank XYZ sendiri alat tulis kantor merupakan kebutuhan utama dalam menunjang kinerja karyawan khususnya bagian administrasi. Hampir seluruh aktivitasnya menggunakan alat tulis kantor sebagai pendukung kelancaran operasional. Proses permintaan alat tulis kantor saat ini masih dilakukan secara semi komputerisasi yaitu masing-masing divisi mengisi formulir yang telah disediakan oleh bagian purchasing, kemudian formulir tersebut diajukan ke pimipinan unit masing-masing untuk disetujui, jika formulir disetujui maka formulir tersebut diserahkan ke bagian purchasing. Pembelian ATK dalam sebulan dilakukan sebanyak 2 kali setelah purchasing staff menerima open pre-order dari setiap divisi di awal bulan mulai tanggal 1 sampai 3 dan pertengahan bulan pada tanggal 13 sampai 15. Oleh karena 
itu masing-masing divisi harus mengontrol dengan baik penggunaan alat tulis kantor. Permasalahan yang sering terjadi yaitu supplier ATK yang belum sepenuhnya bisa dikontrol oleh bagian purchasing serta pemilihan supplier yang belum sesuai peraturan perusahaan, sehingga kualitas ATK tidak sesuai dengan yang diharapkan yang menyebabkan hubungan kerjasama perusahaan dengan supplier tidak berlangsung lama. ATK yang paling banyak digunakan adalah kertas. Setiap bulannya bagian purchasing menerima order dari berbagai divisi sekitar 200 sampai 300 rim kertas. Karena banyaknya pemesanan ATK serta kurangnya kontrol kualitas barang dari supplier, tidak sedikit ATK yang dibeli kualitasnya kurang memenuhi standar perusahaan. Misalkan pada pembelian kertas, dalam 1 rim banyak ditemukan kertas yang saling menempel, warnanya tidak sama bahkan ada juga yang rusak dan tidak dapat digunakan. Sehingga persediaan kertas menjadi berkurang dan menghambat kegiatan operasional kantor. Hal ini jika sering terjadi akan merugikan perusahaan. Oleh karna itu bagian purchasing harus melakukan pemilihan supplier ATK secara optimal dengan berbagai kriteria sesuai peraturan perusahaan sehingga dapat mengembangkan hubungan kerjasama yang baik dan jangka waktu yang panjang dengan supplier.

\section{KAJIAN PUSTAKA}

\subsection{Manajemen Logistik}

Menurut Bowersox (2002:13) manajemen Logistik adalah unik karena ia merupakan satu aktivitas perusahaan yang tertua tetapi juga termuda. Logistik merupakan proses pengelolaan yang strategis terhadap pemindahan dan penyimpanan barang, suku cadang dan barang jadi dari para suplaier, di antara fasilitasfasilitas perusahaan dan kepada para langganan. Aktivitas logistik (lokasi fasilitas, transportasi, inventarisasi, komunikasi, dan pengurusan dan penyimpanan) telah dilaksanakan orang semenjak awal spesilisasi komersil. Logistik atau Supply Chain adalah kegiatan pengumpulan fungsional (transportasi, persediaan, kontrol, dll) yang diulang berkalikali di seluruh chanel di mana bahan baku diubah menjadi produk jadi dan nilai konsumen ditambahkan.

Secara umum kegiatan logistik terdiri dari 2 (dua) kegiatan yaitu kegiatan pergerakan (move) dan kegiatan penyimpanan (store), sehingga jika kedua kegiatan ini direncanakan dan dikendalikan secara ketat, maka masalah sistem logistik secara keseluruhan akan dapat terselesaikan dengan baik. Dua kegiatan utama tersebut diurai menjadi beberapa kegiatan yaitu pemrosesan pesanan, transportasi, persediaan, penanganan barang, struktur fasilitas dan sistem informasi dan komunikasi. Ketujuh kegiatan itu disebut juga sebagai bauran kegiatan logistik (logistics activity mix) dimana semua kegiatan tersebut tidak dapat dihindarkan keberadaannya dalam sebuah sistem rantai pasok (Supply Chain System).

\subsection{Pemilihan Supplier}

Menurut William J Stevenson (2002 : 701) pemilihan supplier biasanya mempertimbangkan kualitas dari produk, service atau pelayanan dan ketepatan waktu pengiriman adalah hal yang penting, meskipun ada beberapa faktor lain yang harus dipertimbangkan. Pemilihan supplier didefinisikan sebagai proses untuk menemukan supplier yang mampu menyediakan pembeli dengan hak kualitas produk atau jasa dengan harga yang tepat, tepat jumlah dan pada waktu yang tepat. Pemilihan supplier yang tepat merupakan faktor penting yang mempengaruhi berakhirnya hubungan pembeli-supplier, jika proses ini dilakukan dengan benar, maka hubungan pembeli-supplier akan bertahan lama.

Menurut Pujawan \& Mahendrawathi (2017:187) memilih supplier merupakan kegiatan strategis, terutama apabila supplier tersebut akan memasok item yang kritis atau akan digunakan dalam jangka panjang sebagai supplier penting. Kriteria pemilihan adalah salah satu hal penting dalam pemilihan supplier. Kriteria yang digunakan tentunya harus mencerminkan strategi supply chain maupun karakteristik dari item yang akan dipasok. Secara singkat, proses pemilihan supplier sebagai berikut :

1. Tentukan kriteria-kriteria pemilihan

2. Tentukan bobot masing-masing kriteria

3. Indentifikasi alternatif (supplier) yang akan dievaluasi

4. Evaluasi masing-masing alternative dengan kriteria di atas

5. Hitung nilai berbobot masing-masing supplier

6. Urutkan supplier berdasarkan nilai berbobot tersebut 
Kinerja supplier perlu dimonitor secara kontinu. Penilaian atau monitoring kinerja ini penting dilakukan sebagai bahan evaluasi yang nantinya bisa digunakan untuk meningkatkan kerja atau sebagai bahan pertimbangan perlu atau tidaknya mencari supplier alternatif. Hubungan supplier tidak selalu jangka panjang dan bersifat kemitraan. Ada situasi ketika hubungan jangka pendek lebih tepat digunakan. Untuk memberikan panduan kapan hubungan harus bersifat kemitraan dan kapan sebaiknya jangka pendek, perusahaan perlu membangun relationship portfolio. Ada dua faktor yang bisa digunakan dalam merancang hubungan dengan supplier.. Yang pertama adalah tingkat kepentingan strategis item yang dibeli bagi perusahaan. Portfolio ini bisa dibentuk dengan memperhatikan tingkat kepentingan item yang akan dibeli dan tingkat kesulitan dalam membeli atau mendapatkan item tersebut. Strategis atau tidaknya suatu item dipengaruhi oleh beberapa hal seperti berikut :

1. Kontribusi item tersebut terhadap kegiatan/kompetensi inti perusahaan

2. Nilai pembelian dalam setahun

3. Image atau brand name dari supplier

4. Risiko ketidaksertaan item yang bersangkutan

Faktor yang kedua adalah tingkat kesulitan mengelola pembelian item tersebut. Samakin tinggi tingkat kesulitannya, semakin banyak diperlukan intervensi dari manajemen. Secara umum tingkat kesulitan pembelian suatu item ditentukan oleh beberapa hal :

1. Kompleksitas dan keunikan item

2. Kemampuan supplier dalam memenuhi permintaan

3. Ketidakpastian (ketersediaan, kualitas, harga, waktu pengiriman)

\subsection{Pengambilan Keputusan}

Pengambilan Keputusan atau Decision Making adalah suatu proses pemikiran dalam pemilihan dari beberapa alternative atau kemungkinan yang paling sesuai dengan nilai atau tujuan individu untuk mendapatkan hasil atau solusi mengenai prediksi kedepan.

Berikut ini beberapa pengertian pengambilan keputusan dari beberapa sumberbuku:

- Menurut Wang dan Ruhe (2007), pengambilan keputusan adalah proses yang memilih pilihan yang lebih disukai atau suatu tindakan dari antara alternative atas dasar kriteria atau strategi yang diberikan.

- Menurut Suharnan (2005), pengambilan keputusan adalah proses memilih atau menentukan berbagai kemungkinan diantara situasi-situasi yang tidak pasti.

- Menurut Terry (2003), pengambilan keputusan adalah pemilihan alternative perilaku dari dua alternative atau lebih, tindakan untuk memecahkan masalah yang dihadapi melalui pemilihan satu diantara alternatif- alternatif yang memungkinkan.

Gaya pengambilan keputusan adalah bagaimana seseorang menginterpretasi, merespon dan cara seseorang bereaksi terhadap situasi yang dihadapinya. Menurut Kuzgun, terdapat empat gaya pengambilan keputusan, yaitu sebagai berikut (Bacanli, 2012):

1. Rational (rasional). Gaya rasional ditandai dengan strategi yang sistematis dan berencana dengan orientasi masa depan yang jelas. Para pembuat keputusan rasional menerima tanggung jawab untuk pilihan yang berasal dari internal locus of control dan aktif, disengaja dan logis.

2. Intuitive (intuisi). Gaya intuisi ditandai dengan ketergantungan pada pengalaman batin, fantasi, dan kecenderungan untuk memutuskan dengan cepat tanpa banyak pertimbangan atau pengumpulan informasi. Para pengambil keputusan intuisi menerima tanggung jawab untuk pilihan, tetapi fokus pada emosional kesadaran diri, fantasi dan perasaan, sering secara impulsif.

3. Dependent (dependen). Gaya pengambilan keputusan dependen, menolak tanggung jawab atas pilihan mereka dan melibatkan tanggung jawab kepada orang lain, umumnya figur otoritas. Dalam arti lain, gaya keputusan ini cenderung atas keputusan orang lain yang mereka anggap sebagai figur otoritas (seperti orang tua, keluarga, teman).

4. Indecisiveness (keraguan). Gaya pengambilan keputusan indecisiveness (keraguan) cenderung menghindari situasi pengambilan keputusan atau tanggung jawab terhadap orang lain. Secara signifikan orang ragu-ragu perlu lebih banyak waktu ketika mereka harus memilih suatu pilihan, tetapi mereka juga lebih selektif dan kurang lengkap dalam pencarian informasi. 


\subsection{Alat Tulis Kantor}

Setiap perusahaan selalu membutuhkan alat tulis kantor (ATK) dalam menyelesaikan kegiatan operasionalnya. Alat tulis kantor berarti barang yang dipakai untuk mengerjakan pekerjaan tulis-menulis (Wursanto,2006:82). Dan menurut Moekijat (2008:150) alat tulis kantor (ATK) mencakup baik kertas, bukubuku, pita mesin tik, tinta, pensil, karet penghapus, jepitan kertas, kartu-kartu, dan sebagainya.

Secara rinci alat-alat yang termaksud alat tulis kantor (Wursanto,2006:83), antara lain :

1. Kertas atau paper (Inggris) atau papier (Belanda), adalah material tata usaha yang berbentuk lembaran untuk keperluan tulis-menulis atau dapat pula digunakan sebagai alat pembungkus. Menurut ukurannya kertas dibedakan menjadi:
a) Kertas ukuran dobel folio
b) Kertas ukuran folio
c) Kertas ukuran kuarto
d) Kertas ukuran setengah folio
e) Kertas ujuran seperempat folio

Menurut jenisnya kertas dibedakan menjadi:
a) Kertas bergaris
b) Kertas polos (tidak bergaris)
c) Kertas HVS (houtvrij Schrift)
d) Kertas tembus atau kertas doorslag
e) Kertas duplikator (kertas pengganda atau kertas stensil)
f) Kertas gambar (teken papier)
g) Kertas isap (blotting papier)
h) Kertas marmer (marmer papier)
i) Kertas minyak (olie papier)
j) Kertas sampul (omslag papier)
k) Kertas cetak biru (blauwdark papier)

2. Buku tulis

3. Potlot atau pensil (merah biru, tinta berwarna)

4. Asahan pensil (potloot sliper)

5. Baki surat (brievenback)

6. Cap (cap huruf, cap tanggalan)

7. Bantalan cap (stamp pad)

8. Pena (ball point)

9. Karbon

10. Penggaris

11. Penghapus (karet atau cairan penghapus)

12. Tinta (tinta gambar, tinta tulis, tinta stensil, tinta cap)

13. Pulpen (vulpen)

14. Lem atau perekat (kental dan cair)

15. Tancapan surat (spindel file)

16. Pengungkit kawat jepret (staple remover)

17. Pembuka surat (letter opener)

18. Sandaran buku (bocken standard)

19. Sit stensil, dll. 


\subsection{Kerangka Pemikiran}

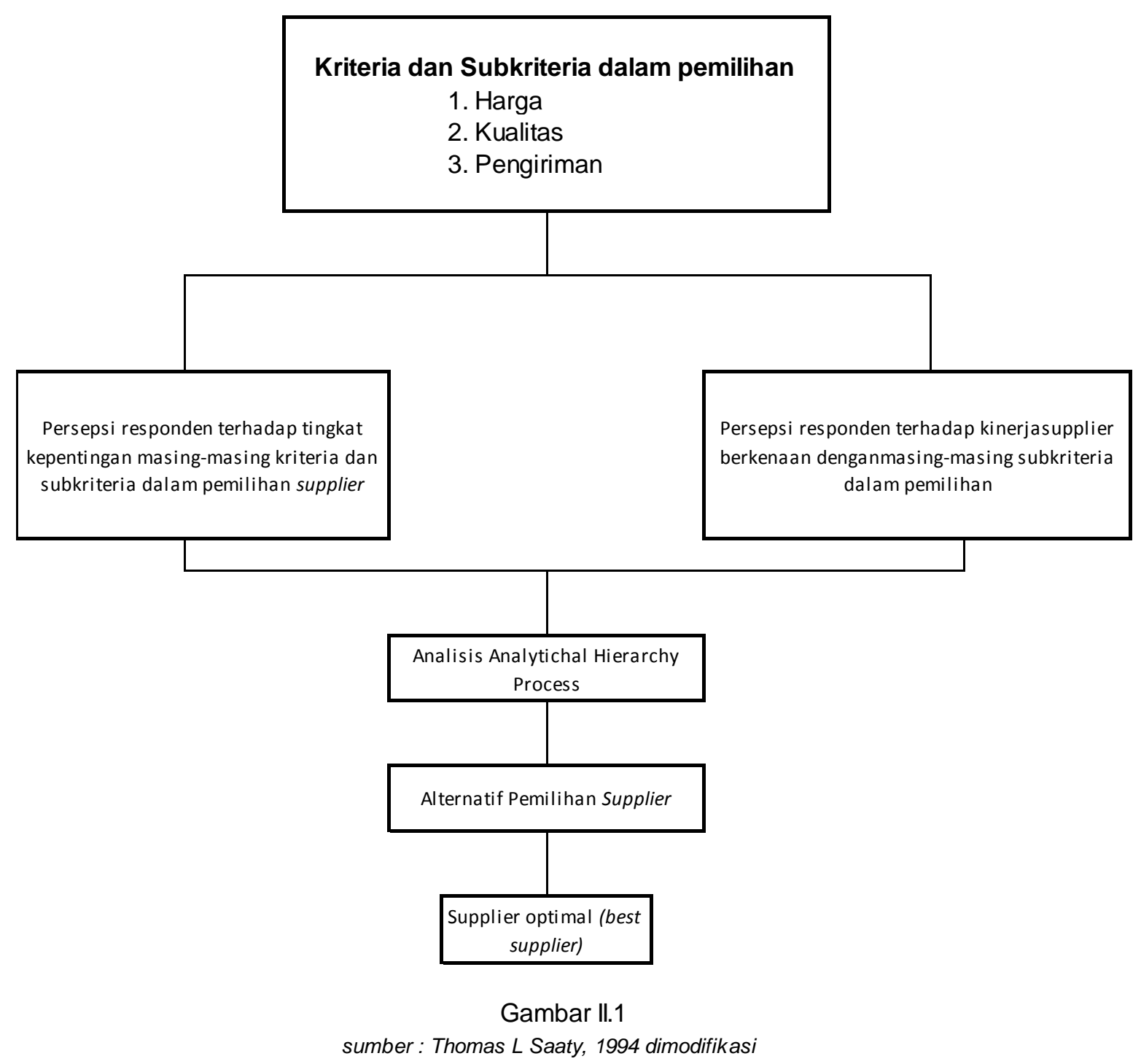

\section{METODOLOGI PENELITIAN}

Pendekatan penelitian ini adalah kuantitafif, dengan teknik pengumpulan data menggunakan kuisioner dan wawancara pendahuluan. Pengertian wawancara menurut Setyadin dalam Gunawan (2013:160), wawancara adalah suatu percakapan yang diarahkan pada suatu proses tanya jawab lisan dimana dua orang atau lebih berhadapan secara fisik.

Penentuan sampel pada penelitian ini dilakukan dengan teknik purposive sampling, di mana pemilihan dilakukan secara sengaja berdasarkan kriteria yang telah ditentukan dan ditetapkan berdasarkan tujuan penelitian. Hal ini dikarenakan metode Analytical Hierarchy Process mensyaratkan ketergantungan pada sekelompok ahli sesuai dengan jenis spesialis terkait dalam pengambilan keputusan. Oleh karena itu, responden dalam penelitian ini adalah :

1. Pihak-pihak yang mempunyai kewenangan mengambil keputusan dalam hal pemilihan supplier, yaitu President Director, Direktur Risk, Compliance \& HC, Network \& Financing Support Group Head, Network \& GA Div. Head, General Services Management Dept. Head

2. Karyawan divisi general affair yang menerima barang secara langsung dari supplier sehingga mengetahui secara langsung kinerja dari supplier.

3. Akademisi dibidang logistic 
Analisis data dilakukan dalam suatu proses, pelaksanaannya mulai dilakukan sejak pengumpulan data dan dilakukan secara intensif. Analisis data yang digunakan dalam penelitian ini adalah metode AHP (Analytical Hierarchy Process). Perhitungan bisa dilakukan secara manual menggunakan Microsoft excel maupun dengan bantuan software expert choice.

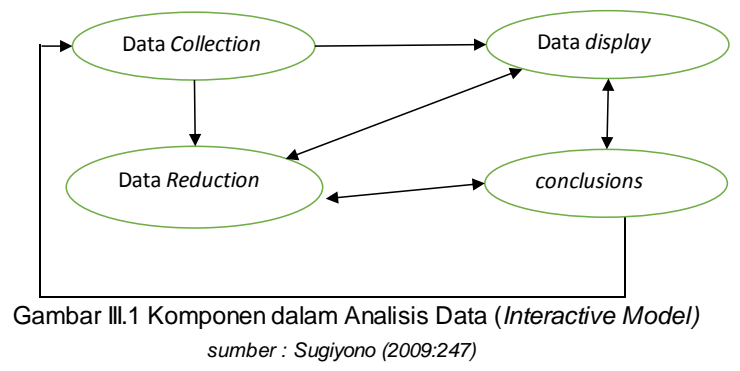

\section{HASIL DAN PEMBAHASAN}

\subsection{Hasil Penelitian}

Metode Analytical Hierarchy Process

\subsubsection{Menyusun Hirarki}

Pada dasarnya metode AHP memecah-mecah suatu situasi ke dalam bagian-bagian komponennya dan menata bagian atau variable ini ke dalam suatu susunan hirarki. Setelah permasalahan didefinisikan, langkah selanjutnya adalah penyusunan model secara hirarki yang terdiri dari beberapa tingkat rincian, yaitu fokus masalah, kriteria, dan alternatif. Fokus masalah merupakan masalah utama yang perlu dicari solusinya dan terdiri hanya satu elemen saja. Kriteria merupakan aspek penting yang perlu dipertimbangkan dalam mengambil keputusan atas fokus masalah. Untuk masalah yang kompleks atau berjenjang, kriteria dapat diturunkan kepada sub-sub kriteria. Yang terakhir adalah alternatif, merupakan berbagai tindakan akhir dan merupakan pilihan keputusan dari penyelesaian masalah yang dihadapi.

Kriteria dalam penelitian ini merupakan kritera yang dipakai oleh perusahaan dalam meilih supplier, yang diperoleh dari hasil wawancara pendahuluan. Masalah pemilihan supplier pada PT Bank XYZ disusun dalam tiga tingkat hirarki seperti pada gambar IV.3.Hirarki tingkat1 merupakan tujuan yaitu pemilihan supplier. Hirarki tingkat 2 merupakan kriteria dalam pemilihan supplier dan hirarki tingkat 3 merupakan alternatif, supplier mana yang sebaiknya dipilih.

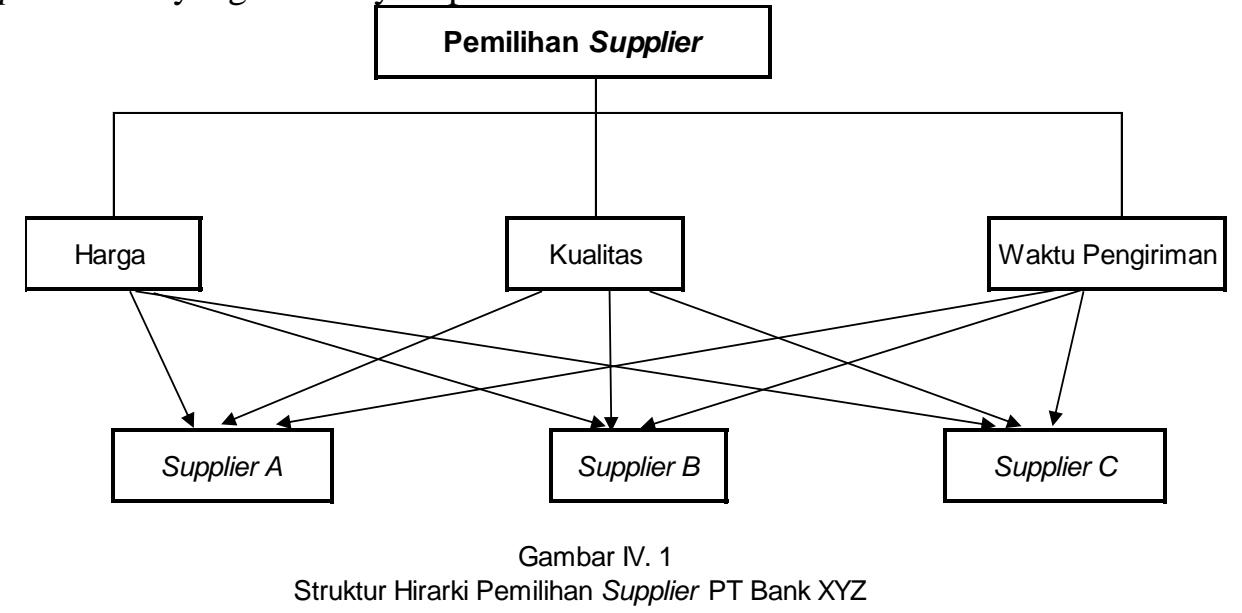

\subsubsection{Membuat Matriks Perbandingan Berpasangan}

Setelah menyusun hirarki, selanjutnya memberikan penilaian tentang kepentingan relatif dua elemen pada suatu tingkat tertentu dalam kaitannya dengan tingkat di atasnya.

\section{a. Matriks Perbandingan Berpasangan Masing-masing Kriteria dalam Pemilihan Supplier pada PT} Bank XYZ 
Agar diperoleh bobot penilaian dari masing-masing variabel maka dibuat table skala penilaian perbandingan berpasangan. Adapun bentuk tabelnya sebagai berikut :

Tabel IV.1

Matriks Perbandingan Berpasangan Tujuan antar Kriteria dalam Pemilihan Supplier

\begin{tabular}{|c|c|c|c|}
\hline Kriteria & Harga & Kualitas & Pengiriman \\
\hline Harga & 1 & & \\
\hline Kualitas & & 1 & \\
\hline Pengiriman & & & 1 \\
\hline
\end{tabular}

sumber : data primer diolah

\section{b. Matriks Perbandingan Berpasangan Alternatif dalam Pemilihan Supplier pada PT Bank XYZ}

Agar diperoleh bobot penilaian dari masing-masing variabel maka dibuat tabel skala penilaian perbandingan berpasangan. Adapun bentuk tabelnya sebagai berikut :

1) Kriteria Harga

2) Kriteria Kualitas

Tabel IV.2

Matriks Perbandingan Berpasangan Tujuan antar Alternatif pada kriteria Harga dalam Pemilihan

\begin{tabular}{|c|c|c|c|}
\hline $\begin{array}{c}\text { Kriteria } \\
\text { Pengiriman }\end{array}$ & Supplier A & Supplier B & Supplier C \\
\hline Supplier $A$ & 1 & & \\
\hline Supplier B & & 1 & \\
\hline Supplier $C$ & & & 1 \\
\hline
\end{tabular}

sumber : data primer diolah

Tabel IV.3

Matriks Perbandingan Berpasangan Tujuan antar Alternatif pada kriteria Kualitas dalam Pemilihan

\begin{tabular}{|c|c|c|c|}
\hline $\begin{array}{c}\text { Kriteria } \\
\text { Pengiriman }\end{array}$ & Supplier A & Supplier B & Supplier $C$ \\
\hline Supplier $A$ & 1 & & \\
\hline Supplier B & & 1 & \\
\hline Supplier C & & & 1 \\
\hline \multicolumn{2}{|c|}{ sumber : data primer diolah }
\end{tabular}

3) Kriteria Pengiriman

Tabel IV.4

Matriks Perbandingan Berpasangan Tujuan antar Alternatif pada kriteria Pengiriman dalam

\begin{tabular}{|c|c|c|c|}
\hline $\begin{array}{c}\text { Kriteria } \\
\text { Pengiriman }\end{array}$ & Supplier $A$ & Supplier $B$ & Supplier $C$ \\
\hline Supplier $A$ & 1 & & \\
\hline Supplier B & & 1 & \\
\hline Supplier $C$ & & & 1 \\
\hline
\end{tabular}

sumber : data primer diolah 
4.1.3. Menghitung bobot/prioritas kepentingan dari masing-masing variabel pada tingkat 2 (kriteria) yaitu Harga, Kualitas dan Pengiriman

Data untuk pengukuran prioritas kepentingan dari kriteria-kriteria dalam pemilihan supplier diperoleh melalui kuisioner yang dibagikan kepada responden yang berjumlah 5 orang yaitu President Director, Direktur Risk, Compliance \& HC, Network \& Financing Support Group Head, Network \& GA Div. Head, General Services Management Dept. Head seperti tabel IV.6

$$
\text { Tabel IV.6 }
$$

\begin{tabular}{l} 
Penilaian Prioritas Kepentingan Kriteria Dalam Pemilihan \\
\begin{tabular}{|c|c|c|c|c|}
\hline Kriteria & Harga & Kualitas & Pengiriman & Average \\
\hline Harga & 0.43 & 0.44 & 0.38 & 0.42 \\
\hline Kualitas & 0.43 & 0.44 & 0.50 & 0.46 \\
\hline Pengiriman & 0.14 & 0.11 & 0.13 & 0.13 \\
\hline Jumlah & 1.00 & 1.00 & 1.00 & 1.00 \\
\hline
\end{tabular} \\
sumber : hasil pengolahan AHP \\
\hline
\end{tabular}

Dari hasil perhitungan perbandingan berpasangan antar variabel dalam memilih supplier di atas di peroleh bobot yang ditunjukan dalam tabel IV.7

Tabel IV.7

Prioritas Kepentingan (bobot) Kriteria dalam pemilihan supplier

\begin{tabular}{|c|c|c|}
\hline Kriteria & Bobot & Prioritas \\
\hline Harga & 0.42 & II \\
\hline Kualitas & 0.46 & $\mathrm{I}$ \\
\hline Pengiriman & 0.13 & $\mathrm{III}$ \\
\hline
\end{tabular}

Tabel IV.7 di atas menunjukan bahwa dalam memilih supplier ATK, prioritas pertama PT. Bank XYZ yaitu kriteria kualitas dengan bobot 0,46 , selanjutnya kriteria harga dengan bobot 0,42 dan prioritas ketiga kriteria pengiriman dengan bobot 0,13 .

4.1.4.Menghitung bobot/prioritas dari masing-masing variabel pada tingkat 3 (altermatif) yaitu bobot setiap supplier dibandingkan dengan masing-masing kriteria

Kriteria Harga

Tabel IV.8

Prioritas kepentingan (bobot) alternatif pada kriteria Harga

\begin{tabular}{|c|c|c|c|c|}
\hline Kriteria & Supplier A & Supplier B & Supplier C & Average \\
\hline Supplier A & 0.19 & 0.17 & 0.44 & 0.27 \\
\hline Supplier B & 0.76 & 0.67 & 0.44 & 0.62 \\
\hline Supplier C & 0.05 & 0.17 & 0.11 & 0.11 \\
\hline Jumlah & 1.00 & 1.00 & 1.00 & 1.00 \\
\hline \multicolumn{4}{|c|}{ sumber : hasil pengolahan AHP } \\
\hline
\end{tabular}

Dari hasil perhitungan perbandingan berpasangan antar variabel kriteria harga diperoleh bobot yang ditunjukan dalam tabel IV.9 berikut : 


\section{Tabel IV.9}

Prioritas Kepentingan (bobot) Kriteria Harga dalam pemilihan supplier

\begin{tabular}{|c|c|c|}
\hline Kriteria & Bobot & Prioritas \\
\hline Supplier $A$ & 0.27 & II \\
\hline Supplier B & 0.62 & I \\
\hline Supplier C & 0.11 & III \\
\hline
\end{tabular}

sumber : hasil pengolahan AHP

Tabel IV.9 di atas menunjukan bahwa pada kriteria harga Supplier B dengan nilai bobot 0,62 merupakan prioritas pertama untuk dipilih. Sedangkan prioritas kedua adalah Supplier A dengan nilai bobot 0,27 dan prioritas ketiga adalah Supplier C dengan nilai bobot 0,11 .

Kriteria Kualitas

\section{Tabel IV.10}

Prioritas kepentingan (bobot) alternatif pada kriteria Kualitas

\begin{tabular}{|c|c|c|c|c|}
\hline Kriteria & Supplier $A$ & Supplier $B$ & Supplier $C$ & Average \\
\hline Supplier $A$ & 0.22 & 0.18 & 0.40 & 0.27 \\
\hline Supplier B & 0.67 & 0.55 & 0.40 & 0.54 \\
\hline Supplier $C$ & 0.11 & 0.27 & 0.20 & 0.19 \\
\hline Jumlah & 1.00 & 1.00 & 1.00 & 1.00 \\
\hline
\end{tabular}

sumber : hasil pengolahan AHP

Dari hasil perhitungan perbandingan berpasangan antar variabel kriteria kualitas diperoleh bobot yang ditunjukan dalam tabel IV.11 berikut :

Tabel IV.11

Prioritas Kepentingan (bobot) Kriteria Kualitas dalam pemilihan supplier

\begin{tabular}{|c|c|c|}
\hline Kriteria & Bobot & Prioritas \\
\hline Supplier $A$ & 0.27 & II \\
\hline Supplier B & 0.54 & I \\
\hline Supplier C & 0.19 & III \\
\hline
\end{tabular}

sumber : hasil pengolahan AHP 
Tabel IV.11 di atas menunjukan bahwa pada kriteria kualitas Supplier B dengan nilai bobot 0,54 merupakan prioritas pertama untuk dipilih. Sedangkan prioritas kedua adalah Supplier A dengan nilai bobot 0,27 dan prioritas ketiga adalah Supplier C dengan nilai bobot 0,19.

Kriteria Pengiriman

Tabel IV.12

Prioritas kepentingan (bobot) alternatif pada kriteria

\begin{tabular}{|c|c|c|c|c|}
\hline \multicolumn{5}{|c|}{ Pengiriman } \\
\hline Kriteria & Trans Retail & Sinar Abadi & Office Pro & Average \\
\hline Supplier A & 0.18 & 0.16 & 0.33 & 0.22 \\
\hline Supplier B & 0.73 & 0.63 & 0.50 & 0.62 \\
\hline Jumlah & 0.09 & 0.21 & 0.17 & 0.16 \\
\hline
\end{tabular}

sumber : hasil pengolahan AHP

Dari hasil perhitungan perbandingan berpasangan antar variabel kriteria pengiriman diperoleh bobot yang ditunjukan dalam tabel IV.13 berikut:

Tabel IV.13

Prioritas Kepentingan (bobot) Kriteria Pengiriman dalam pemilihan supplier

\begin{tabular}{|c|c|c|}
\hline Kriteria & Bobot & Prioritas \\
\hline Supplier $A$ & 0.22 & II \\
\hline Supplier B & 0.62 & I \\
\hline Supplier C & 0.16 & $\mathrm{III}$ \\
\hline
\end{tabular}

sumber : hasil pengolahan AHP

Tabel IV.13 di atas menunjukan bahwa pada kriteria pengiriman Supplier B dengan nilai bobot 0,62 merupakan prioritas pertama untuk dipilih. Sedangkan prioritas kedua adalah Supplier A dengan nilai bobot 0,22 dan prioritas ketiga adalah Supplier C dengan nilai bobot 0,16 .

\subsubsection{Memilih Supplier Optimal}

Setelah masing-masing kriteria dan alternatif didapatkan, kemudian dilakukan sintesis untuk mendapatkan bobot alternatif secara keseluruhan dari kriteria yang ada. Sebelumnya bobot/prioritas lokal (local priority) harus dicari nilai globalnya (global priority) terlebih dahulu. Untuk mendapatkan global priority dengan cara mengalikan local priority dengan prioritas tingkat di atasnya (parent criterion). Secara detail, hasil pembobotan kriteria dan alternatif dapat dilihat dalam tabel IV.14 berikut: 


\begin{tabular}{|c|c|c|c|c|}
\hline & $\begin{array}{r}\text { Tabel } \\
\text { rioritas Glob }\end{array}$ & $\begin{array}{l}14 \\
\text { Globalf }\end{array}$ & & \\
\hline $\begin{array}{l}\text { Tingkat } 1 \\
\text { (Tujuan) }\end{array}$ & $\begin{array}{l}\text { Tingkat } 2 \\
\text { (Kriteria) }\end{array}$ & Bobot & $\begin{array}{c}\text { Tingkat } 3 \\
\text { (Alternatif) }\end{array}$ & Bobot \\
\hline \multirow{9}{*}{$\begin{array}{l}\text { Pemilihan } \\
\text { supplier } \\
\text { optimal } \\
\text { (best } \\
\text { supplier) }\end{array}$} & \multirow{3}{*}{ Harga } & \multirow{3}{*}{0,42} & Supplier A & 0,27 \\
\hline & & & Supplier B & 0,62 \\
\hline & & & Supplier C & 0,11 \\
\hline & \multirow{3}{*}{ Kualitas } & \multirow{3}{*}{0,46} & Supplier A & 0,27 \\
\hline & & & Supplier B & 0,54 \\
\hline & & & Supplier C & 0,19 \\
\hline & \multirow{3}{*}{ Pengiriman } & \multirow{3}{*}{0,13} & Supplier A & 0,22 \\
\hline & & & Supplier B & 0,62 \\
\hline & & & Supplier C & 0,16 \\
\hline
\end{tabular}

Setelah global priority didapatkan, bobot masing-masing alternatif secara keseluruhan dapat dihitung dengan menjumlahkan semua bobot keseluruhan (global priority) pada masing-masing supplier, hasilnya ditunjukan pada tabel IV.15 berikut :

Tabel IV.15

Bobot alternatif secara keseluruhan

\begin{tabular}{|c|c|c|}
\hline Alternatif & Bobot & Prioritas \\
\hline Supplier $A$ & 0,76 & $\mathrm{II}$ \\
\hline Supplier B & 1,78 & $\mathrm{I}$ \\
\hline Supplier $C$ & 0,46 & $\mathrm{III}$ \\
\hline
\end{tabular}

sumber : hasil pengolahan AHP

Tabel IV.15 diatas menunjukan bahwa secara keseluruhan, Supplier B dengan nilai bobot 1,78 merupakan prioritas pertama untuk dipilih sebagai supplier ATK pada PT Bank XYZ. Prioritas kedua adalah Supplier A dengan nilai bobot 0,76, sedangkan prioritas ketiga adalah Supplier $C$ dengan nilai bobot 0,46. berikut ini :

Pemilihan supplier jika dilihat dari pada masing-masing kriteria dapat dilihat pada tabel IV.16

Tabel IV.16

Bobot alternatif secara keseluruhan

\begin{tabular}{|c|c|c|c|}
\hline Kriteria & Supplier A & Supplier B & Supplier C \\
\hline Harga & 0,27 & 0,62 & 0,11 \\
\hline Kualitas & 0,27 & 0,54 & 0,19 \\
\hline Pengiriman & 0,22 & 0,62 & 0,16 \\
\hline
\end{tabular}

sumber : hasil pengolahan AHP 
Tabel IV.16 di atas menunjukan bahwa Supplier B unggul pada semua kriteria, sedangkan Supplier A menjadi prioritas kedua dan prioritas terakhir adalah Supplier $C$.

\subsubsection{Mengukur Konsistensi}

Pengukuran konsistensi ini dimaksudkan untuk melihat ketidakkonsistenan respon yang diberikan responden. Jika $\mathrm{CR}<0,1$ maka nilai perbandingan berpasangan pada matriks kriteria yang diberikan konsisten. Begitu juga sebaliknya, jika $C R>0,1$ maka nilai perbandingan berpasangan pada matriks kriteria yang diberikan tidak konsisten. Sehingga jika tidak konsisten, maka pengisian nilai-nilai matriks berpasangan pada unsur kriteria maupun alternatif harus diulang.

Dari matriks yang dinormalisasikan, kalikan nilai proritas relative dengan setiap entri pada kolom terkait dalam matriks pembandingan. Jumlahkan hasil perkalian dalam baris.

Tabel IV. 17

Matriks Pembandingan yang di Bobot

\begin{tabular}{|c|c|c|c|c|}
\hline \multicolumn{5}{|c|}{ Matriks Pembandingan yang di Bobot } \\
\hline Kriteria & Harga & Kualitas & Pengiriman & Jumlah \\
\hline Harga & 0.42 & 0.46 & 0.38 & 1.25 \\
\hline Kualitas & 0.42 & 0.46 & 0.51 & 1.38 \\
\hline Pengiriman & 0.14 & 0.11 & 0.13 & 0.38 \\
\hline
\end{tabular}

Selanjutnya, pada kolom jumlah baris, bagi setiap entrinya dengan entri yang sesuai dengan vector prioritas. Hasilnya berupa vector konsistensi. Selanjutnya dapat dilihat pada tabel berikut :

Tabel IV. 18

Perhitungan Vektor Konsistensi

(Jumlah / Vektor Prioritas)

\begin{tabular}{|c|c|}
\hline Kriteria & Vektor Konsistensi \\
\hline Harga & 3.01 \\
\hline Kualitas & 3.01 \\
\hline Pengiriman & 3.00 \\
\hline average $\lambda$ & 3.01 \\
\hline
\end{tabular}

Nilai lamda $\lambda$ adalah rata=rata dari vektor konsistensi $=3,01$. Selanjutnya dihitung indeks konsistensi (CI), dimana $\mathrm{n}=3$ (jumlah alternatif yang dibandingkan)

$$
\mathrm{Cl}=\frac{\lambda-\mathrm{n}}{\mathrm{n}-1}=\frac{3,01-3}{3-1}=0,005
$$

Untuk $\mathrm{n}=3$, indeks acak (random index) $=0.58$, sehingga rasio konsistensinya adalah :

$$
C R=\frac{C l}{R I}=\frac{0,005}{0,58}=0,008
$$

Hasil perhitungan $\mathrm{CR}$ di atas, menunjukan nilai $\mathrm{CR}=0,008$ berarti respon cukup konsisten dan tidak perlu diulang lagi.

\subsection{Pembahasan}

Berdasarkan permasalahan yang sering terjadi yaitu supplier ATK yang belum sepenuhnya bisa dikontrol oleh bagian purchasing serta pemilihan supplier yang belum sesuai peraturan perusahaan, sehingga 
kualitas ATK tidak sesuai dengan yang diharapkan dan menyebabkan hubungan kerjasama perusahaan dengan supplier tidak berlangsung lama Hal ini jika sering terjadi akan merugikan perusahaan. Oleh karna itu bagian purchasing harus melakukan pemilihan supplier ATK secara optimal dengan berbagai kriteria sesuai peraturan perusahaan sehingga dapat mengembangkan hubungan kerjasama yang baik dan jangka waktu yang panjang dengan supplier.

Hasil dari wawancara pendahuluan dan kuisioner diperoleh kriteria pemilihan supplier alat tulis kantor yaitu kriteria harga, kriteria kualitas dan kriteria pengiriman sesuai dengan kebijakan perusahaan. Berdasarkan kriteria tersebut urutan prioritas terpenting adalah kriteria kualitas, urutan kedua yaitu kriteria harga dan yang terakhir adalah kriteria pengiriman. Sedangkan untuk calon supplier ATK yaitu Supplier A, Supplier B, dan Supplier C.

Dari hasil analisis Analytical Hierarchy Process di atas, kriteria yang paling berpengaruh dalam pemilihan supplier ATK pada PT Bank XYZ adalah kriteria kualitas dengan bobot 0,46 . Kriteria selanjutnya yang berpengaruh adalah kriteria harga dengan bobot 0,42 serta kriteria pengiriman dengan bobot 0,13 . Hal ini menunjukan bawah PT Bank XYZ mengutamakan kualitas yang tinggi untuk ATK dikarenakan ATK dengan kualitas baik akan berpengaruh pada operasional PT Bank XYZ. Sebaliknya, penggunaan ATK yang kurang berkualitas akan menghambat operasional perusahaan, terutama kinerja karyawannya.

Secara keseluruhan, berdasarkan kriteria-kriteria dalam pemilihan supplier alat tulis kantor, Supplier $B$ menempati prioritas pertama dengan nilai bobot 1,78, sedangkan prioritas kedua adalah Supplier A dengan nilai bobot 0,76 dan prioritas ketiga adalah Supplier $C$ dengan nilai bobot 0,46 . Hal ini menunjukan bahwa secara keseluruhan supplier terbaik yang akan dipilih oleh perusahaan untuk dijadikan sebagai rekanan atau mitra jangka panjang adalah Supplier B karena secara keseluruhan supplier ini memiliki nilai paling tinggi dibandingkan dengan dua supplier lain.

\section{KESIMPULAN DAN SARAN}

\subsection{Kesimpulan}

Berdasarkan tujuan penelitian dan hasil penelitian dari pemilihan supplier alat tulis kantor PT Bank $\mathrm{XYZ}$ di atas maka dapat disimpulkan beberapa hal berikut :

1. Kriteria dalam pemilihan supplier alat tulis kantor yaitu kriteria harga, kriteria kualitas dan kriteria pengiriman, sedangkan urutan prioritas dari kriteria tersebut adalah kriteria kualitas, prioritas kedua yaitu kriteria harga dan prioritas ketiga adalah kriteria pengiriman. Dalam pemilihan supplier alat tulis kantor ada 3 calon supplier yaitu Supplier A, Supplier B dan Supplier C

2. Kriteria yang paling berpengaruh dalam pemilihan supplier ATK pada PT Bank XYZ adalah kriteria kualitas dengan nilai bobot 0,46 . Kriteria selanjutnya yang berpengaruh adalah kriteria harga dengan bobot 0,42 serta kriteria pengiriman dengan nilai bobot 0,13 . Hal ini menunjukan bawah PT Bank XYZ mengutamakan kualitas yang tinggi untuk ATK dikarenakan ATK dengan kualitas baik akan berpengaruh pada operasional PT Bank XYZ

Berdasarkan kriteria-kriteria dalam pemilihan supplier alat tulis kantor, Supplier B menempati prioritas pertama dengan nilai bobot 1,78, sedangkan prioritas kedua adalah Supplier A dengan nilai bobot 0,76 dan prioritas ketiga adalah Supplier $C$ dengan nilai bobot 0,46 . Hal ini menunjukan bahwa secara keseluruhan supplier terbaik yang akan dipilih

\subsection{Saran}

Berdasarkan hasil penelitian dan kesimpulan diatas, maka saran yang dapat diberikan sebagai berikut :

1. Dalam memilih supplier alat tulis kantor, data yang digunakan tidak hanya dari hasil request for information tetapi dari data lain yang dapat memberikan informasi mengenai kriteria-kriteria yang dimiliki supplier. Karena setiap kriteria mempunya bobot yang berbeda, dengan begitu perusahaan bisa mengkombinasikan kriteria-kriteria tersebut untuk mendapatkan supplier alat tulis kantor yang tepat sesuai dengan kebutuhan perusahaan. Dengan memilih supplier alat tulis kantor yang tepat, perusahaan bisa menghemat waktu dan biaya serta bisa mendapatkan kualitas, jenis, serta jumlah yang tepat. Sehingga kegiatan operasional perusahaan dapat berjalan dengan dengan baik.

2. Penelitian dilakukan sebaiknya tidak hanya dengan menggunakan metode Analytical Hierarchy Process (AHP), untuk mengurangi subyektivitas penilaian responden, terutama untuk mengurangi ketidaktepatan 
dan ketidakpastian responden dalam memetakan persepsinya ke dalam angka-angka numerik maka penelitian bisa dilakukan dengan metode lain yang lebih baik sehingga dapat dibandingkan hasil yang lebih tepat.

\section{DAFTAR PUSTAKA}

[1] Agusta, Yudi.2014. Analytical Hierarchy Process. https://yudiagusta.wordpress.com/2014/02/23/analytical-hierarchy-process-ahp/ . Diakses pada tanggal 24 April 2019.

[2] Armstrong dan Philip Kotler.2003.Manajemen Pemasaran, Edisi Kesembilan.Jakarta: PT Indeks Gramedia

[3] Gunawan, Imam. 2013. Metode Penelitian Kualitatif : Teori dan Praktik. Jakarta: PT Bumi Aksara.

[4] Heizer, Jay dan Barry Render.2005. Manajemen Operasi.Edisi Ketujuh. Jakarta: Salemba Empat

[5] Kotler, Philip.2000. Prinsip-Prinsip Pemasaran Manajemen. Jakarta: Prenhalindo

[6] Moekijat.2008.Manajemen Personalia dan Sumber Daya Manusia. Yogyakarta: BFFE

[7] Pujawan, I Nyoman dan Mahendrawathi.2017. Supply Chain Management, Edisi ketiga, Yogyakarta: ANDI

[8] Rahmayanti, Reny.2010. Analisis Pemilihan Supplier Menggunakan Metode Analytical Hierarchy Process (AHP). Skripsi Sarjana: Universitas Sebelas Maret

[9] Sekaran, Uma.2006. Research Metodhs For Business: Metodelogi Penelitian untuk Bisnis. Jakarta: Salemba Empat

[10] Subakti, Irfan.2002. Sistem Pendukung Keputusan. Surabaya: Institut Teknologi Sepuluh November

[11] Sugiyono.2013.Metode Penelitian Kuantitatif, Kualitatif, R\&D, Bandung: C. Alfabeta.

[12] Suharman.2005.Psikologi Kognitif. Surabaya: Srikandi.

[13] Tahriri, Farzad, dkk.2008. A Review of Supplier Selection Methods In Manufacturing Industries.

[14] Terry.2003.Prinsip-Prinsip Management.Jakarta: PT Bumi Aksara

[15] Wang, Y., \& Ruhe, G.R.2007.The Cognitive Process of Decision Making. International Journal of Cognitive Informatics and Natural Intelligence.

[16] Wursanto, Ignatius.2006, Kompetensi Sekretaris.Jakarta:ANDI 